\title{
A Simple Method for Rapid Manufacturing Large-area Hot Embossing Rapid Toolings and its Application
}

\author{
Chil-Chyuan KUO*, Min-Hsiang WU \\ Department of Mechanical Engineering, Ming Chi University of Technology No. 84, Gungjuan Road, New Taipei City \\ 243, Taiwan \\ crossref http://dx.doi.org/10.5755/j01.ms.24.2.13879
}

Received 26 December 2015; accepted 31 January 2016

\begin{abstract}
Hot embossing process has been frequently used in the microfabrication. Developing a low-cost and simple manufacturing method to fabricate a large-area embossing mold is an important issue. The purpose of this study was to propose a cost-effective method for rapid fabricating large-area hot embossing molds with aluminum (Al)-filled epoxy resins. The $1: 0.75$ is the optimal mixture ratio for mixing epoxy resin and recycled Al-filled epoxy resin powders and the optimal thickness for a large-area hot embossing mold is $15 \mathrm{~mm}$. The total manufacturing cost savings about $52.4 \%$ and the last process manufacturing cost savings about $61.6 \%$ can be obtained using the method proposed in this work. A large-area hot embossing mold has smooth mold surfaces and can be carried out in about 3 days. The fabricated largearea hot embossing mold is rigid enough for short runs of parts using hot embossing molding.

Keywords: hot embossing mold, large-area, manufacturing cost.
\end{abstract}

\section{INTRODUCTION}

Quick response to the market was considered as one of the important factors to ensure company competitiveness. To solve this issue, additive manufacturing (AM) [1] and rapid tooling technique (RTT) [2-4] were proposed to reduce the manufacturing cost and manufacturing time to markets. The physical prototypes could be fabricated swiftly by AM technique compared to long lead times taken by traditional machining. RT is capable of replacing conventional steel tooling to reduce cost and time to market [5]. Direct RTT has played important role in the new product development phase [6]. Wang et al. [7] demonstrated an automatic method to design the conformal cooling circuits used for rapid tooling. Iftikhar et al. [8] developed a turbine blade using RTT. Nandi et al. [9] proposed a silicone rubber composite mold material to enhance the solidification rate of soft tooling process. Two important issues in the mold industry are the time and expense needed for producing a mold in the new product development phase. As a result, it is important to develop a cost-effective method for rapid fabricating a large-area hot embossing mold for microfabrication. A cost-effective approach for rapid manufacturing a large-area hot embossing mold was demonstrated to address this important issue. Optimization of the mixture ratios of epoxy resin and recycled Al-filled epoxy resin powders were investigated. The performance of a large-area hot embossing mold was evaluated using hot embossing molding. The total manufacturing cost savings for fabricating a large-area hot embossing mold were also calculated.

\section{EXPERIMENTAL DETAILS}

Fig. 1 shows the process layout for fabricating a largearea hot embossing mold. A room temperature

\footnotetext{
* Corresponding author. Tel: +8862290898994524; fax: +886229063269

E-mail address: jacksonk@mail.mcut.edu.tw (C.C. Kuo)
}

vulcanization silicone rubber (KE-1310ST, Shin Etsu Inc.) and aluminum (Al)-filled epoxy resins (70-3810R, Epoxies Inc.) were used as the mold making materials to fabricate a large-area hot embossing mold. The Al-filled epoxy resins were chosen because it can be a useful alternative of conventional steel mold and employed in hot embossing molding, plastic injection molding or wax injection molding. Fabrication of a large-area hot embossing mold was carried out applying a five-step micro-replication procedure. The cell silicone rubber mold was first fabricated by pouring the mixed silicone rubber resin over the cell mold. The dimensions of a large-area silicone rubber mold are $350 \mathrm{~mm}$ in length and $250 \mathrm{~mm}$ in width. The 25 cell silicone rubber molds were jointed to form a large-area silicone rubber mold. The purpose of this process was to make a large-area silicone rubber mold with positive shape by assembling 25 cell silicone rubber molds. Thus, a large-area silicone rubber mold with negative shape was fabricated by pouring the mixed silicone rubber resin over a large-area silicone rubber mold. Finally, a large-area hot embossing mold with micro-sized structures was fabricated by pouring the mixed epoxy resin composites over a large-area silicone rubber mold with negative shape. In this study, two types of methods were employed to fabricate a large-area hot embossing mold. In order to reduce the manufacturing cost, green manufacturing technology was employed to fabricate a large-area hot embossing mold. The recycled pieces of Alfilled epoxy resins were milled into powders using a precision universal milling machine. The recycled Al-filled epoxy resin powders were first mixed with new epoxy resin (174 A, Jasdi Chemicals Inc.) and then poured into the mold frame as backing material for reducing the manufacturing cost of a large-area hot embossing mold. In order to remove air air-bubbles inside the mixtures, all the processes were operated in a vacuum casting machine. To obtain bubble-free silicone rubber mold and hot embossing mold, a vacuum casting machine was employed to eliminate air-bubbles in a vacuum condition. The hot 
embossing mold was cured in a convection oven (DH400, Deng Yag Inc.) at $79{ }^{\circ} \mathrm{C}$ for $2 \mathrm{~h}$ followed by $149{ }^{\circ} \mathrm{C}$ for $3 \mathrm{~h}$. The hot embossing mold is a clone of the large-area silicone rubber and has negative microfeatures of the master model. After post-cure heat treatment, the hot embossing mold has good mechanical properties for pilot run using the hot embossing because hot embossing is a low-cost processing approach for polymer-based microfabrication. The Acrylonitrile Butadiene Styrene (ABS) (PA-747S, Chi Mei Inc.) was used as the molding material since it can be easily patterned using hot embossing molding. The large sheet of the ABS materials was cut into square pieces of $250 \mathrm{~mm} \times 350 \mathrm{~mm}$. The samples were cleaned in an ultrasonic cleaner with ethanol before hot embossing molding. The processing parameters for hot embossing molding are embossing temperature of $180{ }^{\circ} \mathrm{C}$ and press force of $200 \mathrm{~N}$. The embossed dimensions of microstructures were examined using an optical microscopy.

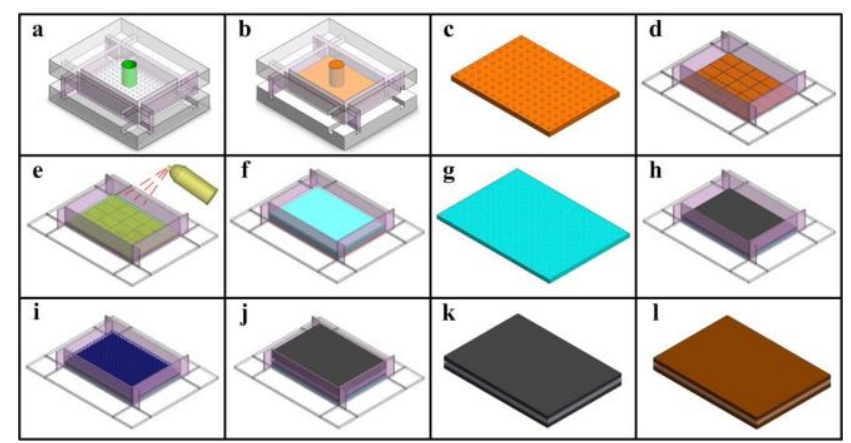

Fig. 1. Process layouts for fabricating a large-area hot embossing mold: $a$-machining of a cell mold; $b$-pouring liquid silicone rubber; $\mathrm{c}$-fabrication of a cell silicone rubber mold; $d$-fabrication of a large-area silicone rubber mold by assembling 25 cell silicone rubber molds; e-spraying the release agent; $f$-pouring liquid silicone rubber; $g-a$ large-area silicone rubber mold; $\mathrm{h}$ - pouring new Al-filled epoxy resins; $\mathrm{i}$-pouring backing materials; $\mathrm{j}$-pouring new Al-filled epoxy resins; $\mathrm{k}$-large-area hot embossing mold; 1-post cure of the large-area hot embossing mold

The solid model preparation was carried out with the software Solidworks. Hexagonal 3D quadratic stress elements, SOLID 95, were used for mashing the part [10]. The Young's modulus and the Poisson's ratio of the epoxy resin were determined from the results of mechanical testing using a universal testing machine (Insight 5 SL, MTS system Inc.).The Young's modulus for the new epoxy resins and recycled epoxy resins are about 9.9 GPa and $3.7 \mathrm{GPa}$, respectively. The Poisson's ratio for the new epoxy resins and recycled epoxy resins are about 0.32 and 0.27 , respectively. Boundary conditions were applied to the embossed areas. The applied load is about $650 \mathrm{~N}$. Maximum stresses of a large-area hot embossing mold were investigated by finite element method using ANSYS software[11, 12].

\section{RESULTS AND DISCUSSION}

Fig. 2 shows the dependence of the compressive strength on the mixing ratios of epoxy resin and recycled Al-filled epoxy resin powders. The results show that the $1: 0.75$ is the optimal mixture ratio for mixing epoxy resin and recycled Al-filled epoxy resin powders due to highest compressive strength.

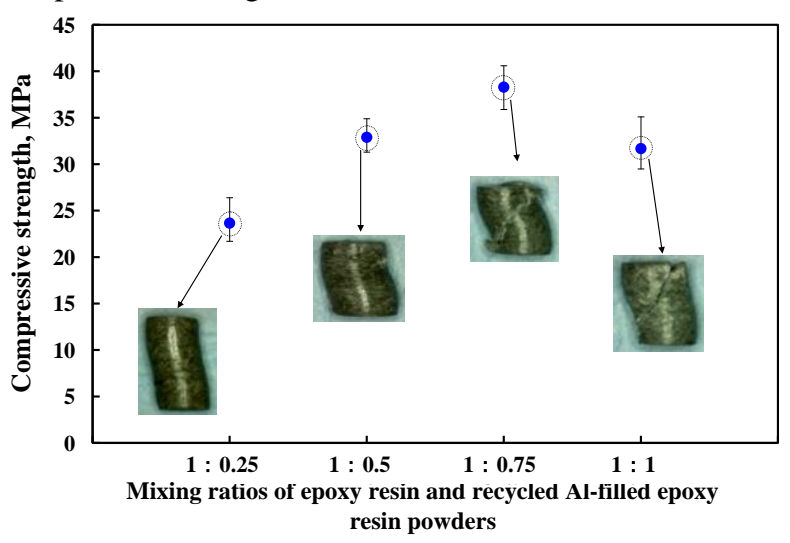

Fig. 2. Dependence of the compressive strength on the mixing ratios of epoxy resin and recycled Al-filled epoxy resin powders

Fig. 3 shows the dependence of the maximum stresses on different mold thickness. It is seen that the maximum stress reduces as the mold thickness increases from $9 \mathrm{~mm}$ to $14 \mathrm{~mm}$ and saturate at mold thickness of $15 \mathrm{~mm}$. This means that the optimal thickness for a large-area hot embossing mold is $15 \mathrm{~mm}$. The $15 \mathrm{~mm}$ thick hot embossing mold is composed of surface layer, an intermediate layer and the bottom layer. The thicknesses of the three layers were $3 \mathrm{~mm}, 9 \mathrm{~mm}$ and $3 \mathrm{~mm}$, respectively.

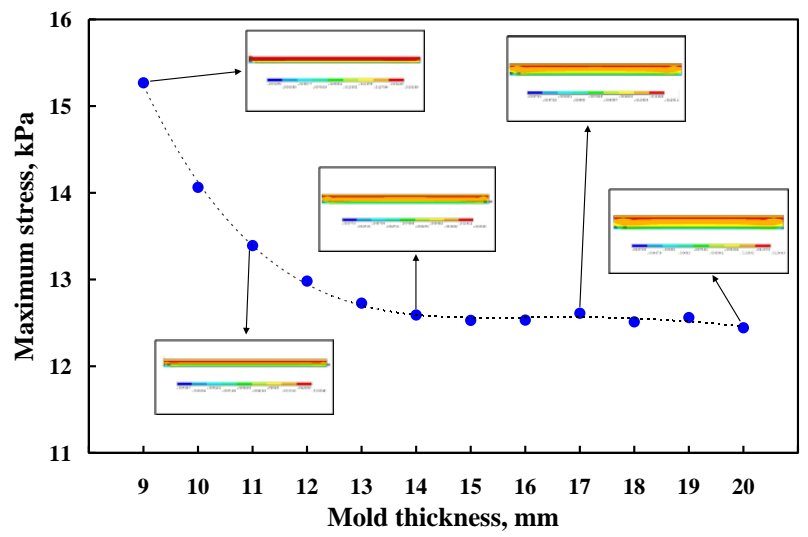

Fig. 3. Dependence of the maximum stresses on different mold thickness. Inserts stand for the Von Mises stress distribution after simulation.

In this study, two different approaches were employed for fabricating the large-area hot embossing mold. In principle, the major factor that affects the total production costs is the usage volume of new Al-filled epoxy resins. The total production costs of a large-area hot embossing mold fabricated by the method proposed by this work is only NT 4,484, while that of a large-area hot embossing mold fabricated by traditional method is NT 9,421. The total manufacturing cost savings about $52.4 \%$ and the last process manufacturing cost savings about $61.6 \%$. This is because a critical step in the mold making processes is that the mixtures of recycled Al-filled epoxy resin powders were used as backing materials. It is interesting to note that the method proposed in this work meets the objective of green manufacturing [13] and has a significant industrial application value due to the cost reduction increases with increasing the dimensions of the fabricated large-area hot 
embossing mold. Thus, the method proposed in this work is a cost-effective method for fabricating large-area rapid tooling. Fig. 4 shows a large-area hot embossing mold with areas of $25 \mathrm{~cm} \times 35 \mathrm{~cm}$. It should be noted that the largearea hot embossing mold has smooth mold surfaces and can be carried out in about 3 days.

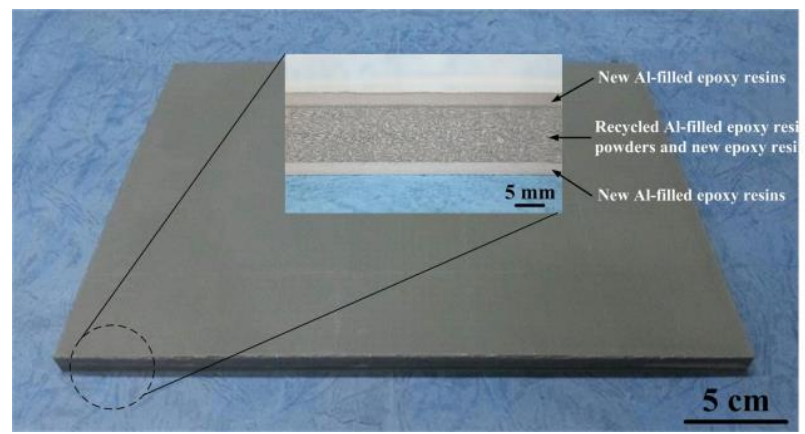

Fig. 4. A large-area hot embossing mold with areas of $25 \mathrm{~cm} \times 35 \mathrm{~cm}$ was fabricated using green manufacturing technology

To evaluate the transcription rate of the hot-embossed parts, 10 parts were embossed using hot embossing molding. Fig. 5 shows a typical hot-embossed part fabricated by a large-area hot embossing mold. The average dimensions in the width and depth of hotembossed embossed parts are $847.3 \mu \mathrm{m}$ and $98.7 \mu \mathrm{m}$, respectively. Hence, the transcription rates in the width and depth are $99.6 \%$ and $98.7 \%$ since the reference dimensions in the width and depth of hot embossing mold are $851 \mu \mathrm{m}$ and $100 \mu \mathrm{m}$, respectively. This result indicates that the embossed parts have acceptable transcription rate and the transcription rate up to $99 \%$ can be obtained. Three phenomena can be observed from this figure. First, the micro-sized structures of surface texture can be fabricated with a large-area hot embossing mold using hot embossing molding. Second, the microstructures on the edges of the hot-embossed parts can be replicated. Third, the hot-embossed parts with minimal warpage were observed. This drawback could be resolved when the embossed materials were changed to ABS because of low glass transaction temperature compared to Polypropylene. A large-area hot embossing mold was then employed for small-batch productions using hot embossing molding.

It is apparent that the method proposed in this work for fabricating a large-area hot embossing mold with microstructures is a cost-effective and simple process because this method requires no special skill or equipment compared to Lithographie Galvanoformung Abformung micromaching, laser micromaching, five-axis computer numerical control micromaching and electroforming [14]. The thermal conductivity of a large-area hot embossing mold is an important issue in the hot embossing molding because higher thermal conductivity provides higher productivity during mass production. In principle, cycle times in the hot embossing molding relate to the thermal conductivity of the mold. The thermal conductivity of a large-area hot embossing mold is low compared to steel mold. Shortening cycle times in mass production are really an important issue for a large-area hot embossing mold. Further investigation is necessary to equip with conformal cooling channels [15-17] in a large-area hot embossing mold for shortening cycle time during hot embossing molding. In addition, optimization of hot embossing molding process parameters using Taguchi method is in progress [18].

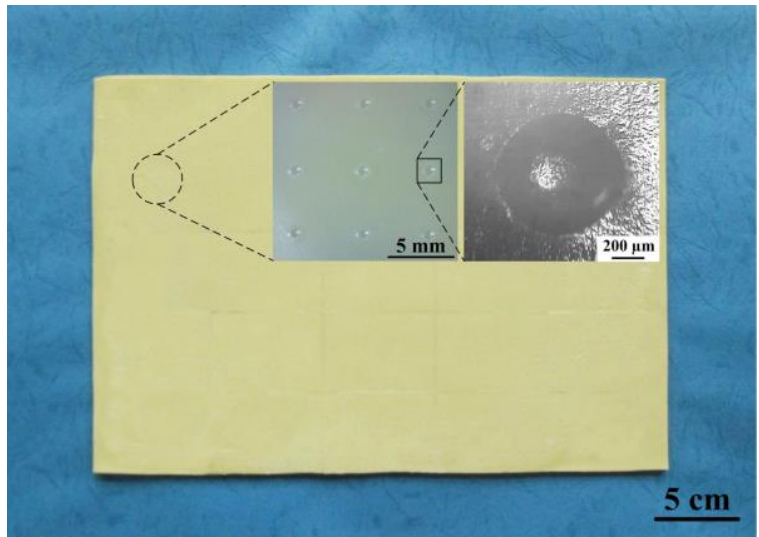

Fig. 5. A typical hot-embossed part fabricated by a large-area hot embossing mold

\section{CONCLUSIONS}

A cost-effective approach for rapid manufacturing large-area hot embossing molds with Al-filled epoxy resin has been demonstrated. Based on the results discussed in this study, the following conclusions can be drawn:

1. A high-precision hot embossing mold with areas of $250 \mathrm{~mm} \times 350 \mathrm{~mm}$ has been fabricated using green manufacturing process. The proposed manufacturing process provides a simple, cost-effective, rapid and efficient way of manufacturing a large-area precision hot embossing mold with micro-sized structures.

2. A large-area hot embossing mold can be carried out in about 3 days.

3. The optimal thickness for a large-area hot embossing mold is $15 \mathrm{~mm}$. The total manufacturing cost savings about $52.4 \%$ and the last process manufacturing cost savings about $61.6 \%$ can be obtained.

4. The optimal mixture ratio of $1: 0.75$ has been employed for mixing epoxy resin and recycled Alfilled epoxy resin powders.

5. The large-area hot embossing mold has been successfully employed for pilot run using hot embossing molding.

\section{Acknowledgments}

The authors gratefully acknowledge the financial support of the Ministry of Science and Technology of Taiwan under contract no. MOST 103-2221-E-131-012.

\section{REFERENCES}

1. Masood, S.H. Introduction to Advances in Additive Manufacturing and Tooling Comprehensive Materials Processing 10 2014: pp. 1-2. https://doi.org/10.1016/B978-0-08-096532-1.01016-5

2. Kuo, C.C., Liao, H.Y. Enhancing the Mechanical Properties of Epoxy Resin Mold by Adding Zirconia Particles Materials and Manufacturing Processes 29 (7) 2014: pp. $840-847$.

https://doi.org/10.1080/10426914.2014.912311

3. Kuo, C.C., Hsu, H.J. Development and Application of Hybrid Mold with Microfeatures in Micro-hot 
Embossing Materials and Manufacturing Processes 28 (11) 2013: pp. 1203-1208.

https://doi.org/10.1080/10426914.2013.832305

4. Kuo, C.C., Hsu, H.J. Micro-hot Embossing of Fresnel Lens Using Precision Micro-featured Mold Materials and Manufacturing Processes 28 (11) 2013: pp. 1228-1233. https://doi.org/10.1080/10426914.2013.811748

5. Kuo, C.C. A Simple and Cost-effective Method for Fabricating Epoxy-based Composites Mold Inserts Materials and Manufacturing Processes 27 (4) 2012: pp. 383-388. https://doi.org/10.1080/10426914.2011.551906

6. Rahmati, S. Direct Rapid Tooling Comprehensive Materials Processing 10 2014: pp. 303-344. https://doi.org/10.1016/B978-0-08-096532-1.01013-X

7. Wang, Y., Yu, K.M., Wang, C.C.L., Zhang, Y. Automatic Design of Conformal Cooling Circuits for Rapid Tooling Computer-Aided Design 43 2011: pp. 1001-1010. https://doi.org/10.1016/j.cad.2011.04.011

8. Iftikhar, A., Khan, M., Alam, K., Jaffery, S.H.I., Ali, L., Ayaz, Y., Khan, A. Turbine Blade Manufacturing Through Rapid Tooling (RT) Process and Its Quality Inspection Materials and Manufacturing Processes 28 (5) 2013: pp. 534-538. https://doi.org/10.1080/10426914.2012.746698

9. Nandi, A.K., Deb, K., Datta, S. Genetic Algorithm-Based Design and Development of Particle-Reinforced Silicone Rubber for Soft Tooling Process Materials and Manufacturing Processes 28 (7) 2013: pp. 753-760. https://doi.org/10.1080/10426914.2013.773022

10. Kajzer, W., Kaczmarek, M., $\quad$ Marciniak, M. Biomechanical Analysis of Stent-oesophagus System Journal of Materials Processing Technology 162-163 2005: pp. 196-202. https://doi.org/10.1016/j.jmatprotec.2005.02.209

11. Schlitzer, T., Bauerbach, K., Beier, H.T., Fischaleck, M., Langschwager, K., Oechsner, M., Rudolph, J., Scholz, A., Vormwald, M., Willuweit, A. Experimental Characterization and Numerical Assessment of Fatigue Crack Growth Under Thermo-mechanical Conditions
Materialwissenschaft und Werkstofftechnik 46 (2) 2015: pp. $165-177$.

https://doi.org/10.1002/mawe.201400372

12. Martínez-Figueroa, J., Rubio-Gonzalez, C., VelascoReyes, F. Three Point Bending Hopkinson Bar for Fracture Toughness Measurement: A New Approach for Interface Analysis Materialwissenschaft und Werkstofftechnik 46 (4-5) 2015: pp. 505-514. https://doi.org/10.1002/mawe.201500426

13. Kuo, C.C. Development of Green Rapid Tooling technologies Indian Journal of Engineering and Materials Sciences 20 (4) 2013: pp. 245-251. https://doi.org/10.1016/j.msea.2012.11.011

14. Kuo, C.C., Zhuang, B.C. Manufacturing Process Development of a Precision Rapid Tooling with Highaspect-ratio Micro-sized Features Materialwissenschaft und Werkstofftechnik 47 (1) 2016: pp. 29-36. https://doi.org/10.1002/mawe.201500455

15. Shayfull, Z., Sharif, S., Zain, A.M., Saad, R.M., Fairuz, M.A. Milled Groove Square Shape Conformal Cooling Channels in Injection Molding Process Materials and Manufacturing Processes 28 (8) 2013: pp. 884-891. https://doi.org/10.1080/10426914.2013.763968

16. Armillotta, A., Baraggi, R., Fasoli, S. SLM Tooling for Die Casting with Conformal Cooling Channels The International Journal of Advanced Manufacturing Technology 71 (1) 2014: pp. 573-583. https://doi.org/10.1007/s00170-013-5523-7

17. Lim, W.S., Choi, H.S., Ahn, S.Y., Kim, B.M. Cooling Channel Design of Hot Stamping Tools for Uniform HighStrength Components In Hot Stamping Process Journal of Advanced Manufacturing Technology 70 (5) 2014: pp. $1189-1203$. https://doi.org/10.1007/s00170-013-5331-0

18. Kuo, C.C. Optimization of Hot Embossing Molding process Parameters of Fresnel Lens using Taguchi Method Materialwissenschaft und Werkstofftechnik 46 (9) 2015: pp. $942-948$.

https://doi.org/10.1002/mawe.201500443 